\title{
Özgün araştırma makalesi \\ Süt molar diş çekimi sırasında 3D video gözlük kullanımının çocuklarda ağrı ve anksiyete üzerine etkisi
}

\author{
Zeliha Hatipoğlu Palaz iD, ${ }^{*}$ Erdem Palaz, Neşe Akal \\ Çocuk Diş Hekimliği Anabilim Dalı, Diş Hekimliği Fakültesi, \\ Gazi Üniversitesi, Ankara, Türkiye
}

\section{Özet}

AmAÇ: Çocuk diş hekimleri, dental tedaviler sırasında hastalarının ağrı ve anksiyetesini kontrol altına almak için pek çok yöntem kullanmaktadır. Dikkat dağıtma yöntemi, çocuk hastalarda bu amaçla sık kullanılan davranış yönlendirme tekniklerinden biridir. Bu çalışmanın amacı, görsel ve işitsel dikkat dağıtma sağlayan 3D video gözlüğün 6-10 yaş arası çocuklarda süt molar dişlerin çekimi sırasında kullanımının anksiyete ve ağı üzerine olan etkinliğinin değerlendirilmesidir.

GeREÇ Ve YönTEM: 6-10 yaş aralığındaki 60 çocuk, her grupta $15 \mathrm{kız}, 15$ erkek olacak şekilde rastgele 2 gruba ayrıldı. 1. grupta bulunan 30 hastaya 'Anlat-göster-uygula' yöntemi uygulanarak; 2. grupta bulunan 30 hastaya ise 3D video gözlük ile çizgi film izletilerek diş çekimi yapıldı. Çocukların anksiyete değerlendirmeleri tedaviye başlamadan önce, lokal anestezi sırasında ve lokal anestezi yapıldıktan sonra nabız ve oksijen saturasyon ölçümleri ve MCDAS (Modified Child Dental Anxiety Scale) skorları ile yapıldı. Ağıı algısı, hem lokal anestezi sonrası hem de diş çekimi sonrasında Wong-Baker (W-B) skalası ile kaydedildi.

BULGULAR: 'Anlat-göster-uygula' ve '3D video gözlük' grupları karşılaştırıldığında nabız ve MCDAS skala değerleri bakımından aralarında anlamlı farklılık bulunmadı. Tüm zamanlarda yapılan ölçümlerde '3D video gözlük' grubunun saturasyon değerleri, 'Anlat-göster-uygula' grubuna göre anlamlı derecede daha düșük bulundu. '3D video gözlük' grubunda diş çekimden sonra kaydedilen W-B değerlerinin 'Anlat-göster-uygula' grubuna göre anlamlı derecede düşük olduğu görüldü. '3D video gözlük' grubunda diş çekiminden sonra ölçülen W-B değerinin lokal anestezi sonrasındaki değere göre düşük olduğu gözlendi.

SonUç: Çocuklarda diş çekimi sırasında '3D video gözlük' kullanımının anksiyete değerlerinde beklenen azalmayı

Makale gönderiliș tarihi: 31 Aralık 2019; Yayına kabul tarihi: 7 Nisan 2020 *iletişim: Dr. Zeliha Hatipoğlu Palaz, Gazi Üniversitesi, Diş Hekimliği Fakültesi, Çocuk Diş Hekimliği Anabilim Dalı, Ankara, Türkiye;

E-posta:dt zeliha@hotmail.com sağlamadığı; ağrı algısını ise başarılı bir biçimde azalttığı görülmüştür.

Anahtar Kelimeler: Ağrı algısı; çocuk diş hekimliği; dental anksiyete; sanal gerçeklik

Kaynak Göstermek İçin: Hatipoğlu Palaz Z, Palaz E, Akal N. Süt molar diş çekimi sırasında 3D video gözlük kullanımının çocuklarda ağrı ve anksiyete üzerine etkisi. Acta Odontol Turc 2020;37(3):71-7

ЕрітӧR: Işıl Çekiç Nagaş, Gazi Üniversitesi, Ankara, Türkiye

YAYıN HAKKI: @ 2020 Zeliha Hatipoğlu Palaz ve ark. Bu eserin yayın hakkı Creative Commons Attribution License ile ruhsatlandırımıştır. Sınırsız kullanım, dağıtım ve her türlü ortamda çoğaltım, yazarlar ve kaynağın belirtilmesi kaydıyla serbesttir.

Finansal Destek: Bulunmamaktadır.

ÇıKAR ÇATıŞMASı: Bulunmamaktadır.

[The abstract in English is at the end of the manuscript]

\section{GiRiş}

Anksiyete, kişinin maruz kaldığı bir veya daha fazla durumla ilgili kalıcı bir beklenti ya da endişe olarak tanımlanır. ${ }^{1}$ Diş tedavisine karşı oluşan anksiyete ise bireyin her türlü dental işleme karşı hissettiği korku ve endişe olarak görülmektedir. Ağrı veya ağrı korkusundan kaynaklandığı düşünülen diş tedavisine karşı anksiyete oluşması her yaşta görülmekle birlikte, genellikle çocukluk veya ergenlik döneminde ortaya çıkmaktadır.,3 $\mathrm{Bu}$ anksiyeteye sahip çocukların tedavi yönetiminde farmakolojik (sedasyon ve genel anestezi) veya farmakolojik olmayan ('Anlat-göster-uygula', modelleme ve dikkat dağıtıcı yöntemler gibi) pek çok yöntem kullanılabilmektedir. ${ }^{4,5}$

Dikkat dağıtma yöntemi, yapılan işlem üzerindeki dikkati başka yöne çekmek amacıyla aktif veya pasif formda çeşitli araçların kullanılmasını içermektedir. Aktif formdaki araçlar arasında çocukların oyuncak, sanal gerçeklik ve kontrollü nefes alma gibi duyusal bileşenleri kullanılırken, pasif formda televizyon seyretmek, ışık efektli oda, öykü anlatımı, kulaklık aracılığıyla ses sunumu gibi dikkat dağıtıcılar kullanılır. ${ }^{6}$ Dikkat dağıtıcı yöntemlerin, ağrılı uyaranların yoğunluğunu ve hoşnutsuzluğunu azalttığı bilinmektedir. ${ }^{3}$ Görsel-işitsel dikkat 
dağıtıcı yöntemler basit, güvenli ve ucuzdur; ayrıca diş tedavisine engel olmaz. Özellikle diş tedavileri esnasında izlenen video oyunları ve komedi programlarının hastalar üzerinde dikkat dağıtmada ve ağrı hissinin azalmasında rolü olduğu bildirilmiştir. ${ }^{7}$ Çocuklarda yapılan çalışmalara göre, çeşitli diş tedavileri sırasında görsel-işitsel gözlüklerin kullanımının çocuklardaki anksiyetenin azaltılmasında etkili olduğu görülmektedir. ${ }^{8,9}$ Bu teknik, çocuk ve hekim iletişimine izin verirken, çevre ile olan ilişkiyi kısmen kısıtlamaktadır. Ayrıca çocuğun isteği doğrultusunda farklı videoların yüklenmesine olanak sağlamaktadır. ${ }^{10}$

Görsel-işitsel gözlüklerin, çocuklarda derin dentin çürüğü ve pulpa tedavilerinde kullanılmasıyla ilgili yeterli sayıda çalışma bulunurken, diş çekimi sırasında kullanımı ile ilgili yapılmış yeni çalışmalara rastlanmamıştır. Bu çalışmada; 3D video gözlük kullanımının 6-10 yaş arası çocuklarda lokal anestezi uygulaması ve süt molar dişlerin çekimi sırasında hissedilen anksiyete ve ağrı algısı üzerine olan etkinliğinin değerlendirilmesi amaçlanmıştır.

\section{GeReÇ VE Yöntem}

Çalışmaya dahil edilen çocuklar, Ocak 2016- Nisan 2016 tarihleri arasında Pedodonti kliniğine başvuran ve çekim endikasyonu konulan 6-10 yaşlarındaki çocuklar arasından rastgele seçildi. Etik kurul onayı, Ankara Üniversitesi Diş Hekimliği Fakültesi Etik Kurulundan alındı (13.04.2016, 8/13).

Üst çenesinde tek süt molar dişinde çekim endikasyonu bulunan, daha önce hiç lokal anestezi ve diş çekimi yapılmayan; Frankl davranış skalasına ${ }^{11}$ göre 3 (pozitif) veya 4 (kesinlikle pozitif) olan çocuklar çalışmaya dahil edildi. Herhangi bir sistemik rahatsızlığı bulunan, Frankl skalasına göre skoru 1 veya 2 olan ve daha önce diş çekimi yapılmış olan çocuklar çalışmaya dahil edilmedi. Çalışmaya dahil edilen çocukların ebeveynlerinden, yazılı bilgilendirilmiş onam alındı.

Bu kriterlere göre seçilen 60 çocuk, her grupta 15 kız ve 15 erkek olacak şekilde rastgele 2 gruba ayrıldı. 1. grupta bulunan 30 hastaya (kız, erkek) 'Anlat-göster-uygula' yöntemi uygulanarak; 2. grupta bulunan 30 hastaya ise (kız, erkek) 3D video gözlük (görsel-işitsel) (Virtual Private Theater System 52", Guangdong, Çin) ile çizgi film izletilerek diş çekimi yapıldı (Resim 1). KulIanılan 3D video gözlüğün kulaklıkları yardımıyla işitsel, içinde yüklenmiş bulunan çizgi film izletilerek de görsel dikkat dağıtma yapılması planlandı. Çocukların anksiyete değerlendirmeleri MCDAS (Modified Child Dental Anxiety Scale) ${ }^{12}$ skalasında bulunan 6 soru (1-Diş hekimine gittiğinde genel olarak nasıl hissedersin? 2-Dişlerine bakıldığında nasıl hissedersin? 3-Dişlerin temizlenirken nasıl hissedersin? 4-Dişlerine iğne yapılırken nasıl hissedersin? 5-Dişine dolgu yapılırken nasıl hissedersin? 6-Dişin çekilirken nasıl hissedersin?) sorularak ve her soru için seçilen yüzlere göre 1 ile 5 arası skorlama yapılarak kaydedildi (Şekil 1). Ağrı algıları ise
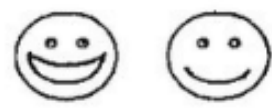

1

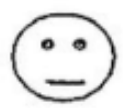

3

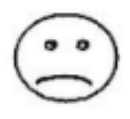

4

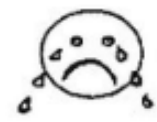

5
Şekil 1. MCDAS Skalası (1-Rahatlamış/endişeli değil, 2-Az endişeli, 3-Oldukça endişeli, 4-Çok endişeli, 5-Çok fazla endişeli)

Wong-Baker FACES Pain Rating Scale

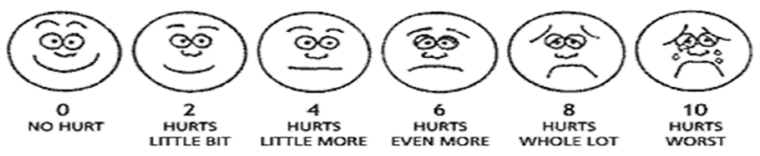

Şekil 2. Wong-Baker Ağrı Skalası (0-Ağrı yok, 2-Biraz ağrı, 4-Birazdan daha fazla ağrı, 6-Daha fazla ağrı, 8-Oldukça fazla ağrı, 10-Şiddetli ağrı)

Wong-Baker (W-B) skalasındaki seçilen yüzlere göre 0-10 arası çift rakamlar ile skorlandırılarak değerlendirildi (Şekil 2).

\section{‘Anlat-göster-uygula' grubu}

Birinci gruptaki hastalar, ünitte $10 \mathrm{dk}$. dinlendirildikten sonra MCDAS skalası uygulandı; ardından pulse oksimetre (Beuer GmbH, Ulm, Almanya) kullanılarak nabız ve saturasyon değerleri kaydedildi. Yapılacak işlemler sırası geldiğinde 'Anlat-göster-uygula' yöntemi kullanılarak sürdürüldü. Hastalara $2 \mathrm{dk}$ süresince topikal anestezi (Locanest sprey, AVIXA İlaç San. ve Tic. Ltd. Şti., İstanbul, Türkiye) uygulandıktan sonra yapılan lokal anestezi (Ultracain forte, Sanofi Sağlık Ürünleri Ltd. Şti, İstanbul, Türkiye) (bukkal ve palatinal bölgenin her birine $0.5 \mathrm{ml}$ anestezik solüsyon zerk edildi) sırasında yeniden nabız ve saturasyon ölçüldü. Lokal anestezi yapıldıktan $1 \mathrm{dk}$ sonra MCDAS, W-B ağrı skalası, nabız ve saturasyon ölçümleri yapıldı. Yüz ifadeleriyle hastanın o an hissettiği hoşnutsuzluğun derecesi, ağrı yok'tan 'şiddetli ağrı'ya değişen ve 0-10 arasındaki çift rakamlarla belirtilen W-B ağrı skalası kullanılarak belirlendi. Diş çekimi yapıldıktan sonra da W-B skalası, nabız ve saturasyon değerleri tekrar ölçülerek kaydedildi. Tüm ölçümler, tedaviyi yapan hekim dışındaki başka bir hekim tarafından yapılarak belirlendi.

\section{‘3D video gözlük' grubu}

İkinci gruptaki hastaların $10 \mathrm{dk}$. dinlenme sonrasında MCDAS skalası verileri, nabız ve saturasyon değerleri kaydedilerek, 3D video gözlüğe yüklenen animasyon filmlerinden (Prenses Sofia, Örümcek Adam, Harika Kanatlar, Winx Club) herhangi birini seçmesi istendi. 3D video gözlük takılarak seçilen çizgi film oynatılmaya başlandı. Hastaya 2 dk. süresince topikal anestezi uygulandıktan sonra yapılan lokal anestezi (bukkal ve palatinal bölgenin her birine $0.5 \mathrm{ml}$ anestezik solüsyon zerk edildi) sırasında, yeniden nabız ve saturasyon ölçüldü. Lokal anestezi yapıldıktan sonra gözlük hastadan çıkartılarak MCDAS, W-B ağrı skalası, nabız ve 
Tablo 1. Grupların nabız ve saturasyon değerleri

\begin{tabular}{|c|c|c|c|c|c|c|c|c|c|c|c|c|}
\hline & & & \multirow{2}{*}{ n } & \multirow[b]{2}{*}{ Ort. } & \multirow[b]{2}{*}{ Ortanca } & \multirow[b]{2}{*}{ Min } & \multirow[b]{2}{*}{ Maks } & \multirow[b]{2}{*}{ SS } & \multicolumn{3}{|c|}{$\begin{array}{l}\text { Friedman's Two Way } \\
\text { ANOVA testi }\end{array}$} & \multirow[t]{2}{*}{$\begin{array}{l}\text { Çoklu } \\
\text { karşılaştırma }\end{array}$} \\
\hline & & & & & & & & & $\begin{array}{l}\text { Sira } \\
\text { ort. }\end{array}$ & Ki-kare & $\mathbf{p}$ & \\
\hline & 3D video gözlük & İşlemden önce & 30 & 104.77 & 105 & 77 & 132 & 11.93 & 1.73 & 8.907 & 0.012 & $1-3$ \\
\hline \multirow{5}{*}{$\frac{N}{\frac{N}{\pi}}$} & & $\begin{array}{l}\text { Lokal anestezi } \\
\text { sonrası }\end{array}$ & 30 & 106.43 & 105 & 77 & 135 & 14.27 & 1.85 & & & \\
\hline & & Çekimden sonra & 30 & 110.47 & 110 & 80 & 139 & 13.22 & 2.42 & & & \\
\hline & Anlat- Göster-Uygula & İşlemden önce & 30 & 102.23 & 101.5 & 74 & 148 & 15.27 & 1.62 & 14.81 & 0.001 & $1-32-3$ \\
\hline & & $\begin{array}{l}\text { Lokal anestezi } \\
\text { sonrası }\end{array}$ & 30 & 103 & 100 & 83 & 142 & 12.89 & 1.83 & & & \\
\hline & & Çekimden sonra & 30 & 112.27 & 111.5 & 79 & 141 & 14.9 & 2.55 & & & \\
\hline \multirow{8}{*}{ 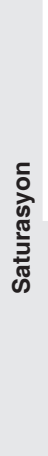 } & 3D video gözlük & İşlemden önce & 30 & 97.03 & 97 & 95 & 99 & 1.25 & 2.67 & 14.696 & 0.002 & $3-4$ \\
\hline & & $\begin{array}{l}\text { Lokal anestezi } \\
\text { sırasında }\end{array}$ & 30 & 96.67 & 97 & 89 & 100 & 2.17 & 2.4 & & & \\
\hline & & $\begin{array}{l}\text { Lokal anestezi } \\
\text { sonrası }\end{array}$ & 30 & 96.27 & 96 & 93 & 98 & 1.34 & 1.92 & & & \\
\hline & & Çekimden sonra & 30 & 97.33 & 97 & 96 & 99 & 1.09 & 3.02 & & & \\
\hline & Anlat- Göster-Uygula & İşlemden önce & 30 & 99.47 & 98 & 95 & 150 & 9.64 & 2.37 & 1.464 & 0.69 & - \\
\hline & & $\begin{array}{l}\text { Lokal anestezi } \\
\text { sırasında }\end{array}$ & 30 & 98.03 & 98 & 95 & 99 & 1.19 & 2.58 & & & \\
\hline & & $\begin{array}{l}\text { Lokal anestezi } \\
\text { sonrası }\end{array}$ & 30 & 98.77 & 98 & 95 & 128 & 5.63 & 2.4 & & & \\
\hline & & Çekimden sonra & 30 & 98.03 & 98 & 94 & 99 & 1.13 & 2.65 & & & \\
\hline
\end{tabular}

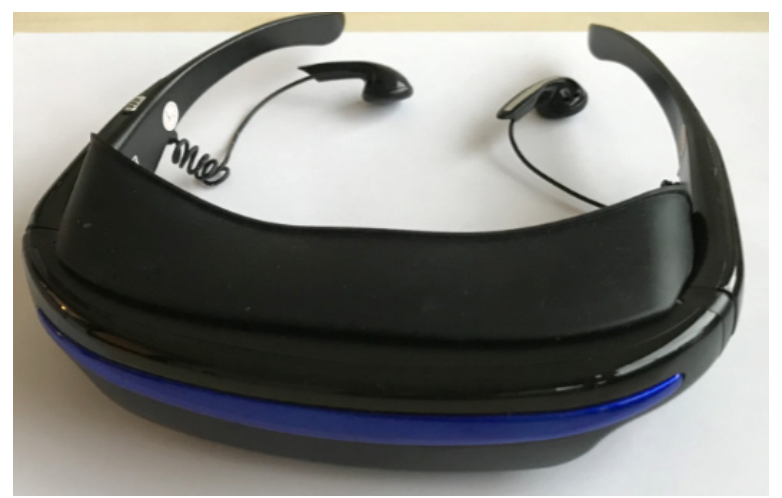

Resim 1. Çocuklara diş çekimi sırasında çizgi film izletilen 3D video gözlük

saturasyon değerleri not edildi. Ardından 3D video gözlük yeniden hastaya takılarak üzerinden $5 \mathrm{dk}$. geçmesi beklendi ve çocuk çizgi film izlediği esnada diş çekimi yapıldı. Diş çekimi yapıldıktan sonra gözlük çıkartıldı ve son olarak W-B skalası, nabız ve saturasyon değerleri kaydedildi.

Çalışma sırasında elde edilen verilerin istatistiksel analizi SPSS 20 paket programı (IBM, New York, NY, ABD) ile yapıldı. Sonuçlar yorumlanırken, anlamlılık düzeyi olarak 0.05 kullanılmış olup; $p<0.05$ olması durumunda değişkenlerin normal dağılımdan gelmediği, p>0.05 olması durumunda ise değişkenlerin normal dağılımdan geldikleri belirtildi. Gruplar arasındaki farklılıklar incelenirken, değişkenlerin normal dağılımdan gelmemesi nedeniyle Mann-Whitney $U$ ve Kruskal-Wallis $\mathrm{H}$ testlerinden yararlanıldı.
Nominal değişkenlerin grupları arasındaki ilişkiler incelenirken ki-kare analizi uygulandı. İkiden çok bağımlı değişkenlerin analizlerinde normal dağılımdan gelmemeleri nedeniyle, Friedman testi kullanıldı. Anlamlı farklılıkların çıkması durumunda, çoklu karşılaştırma testlerinden yararlanılarak birbiriyle farklılık gösteren değişkenler tespit edildi. İki bağımlı değişken arasındaki farklılık incelenirken, değişkenlerin normal dağılımdan gelmemesi nedeniyle Wilcoxon Testi kullanıldı. Sonuçlar yorumlanırken anlamlılık düzeyi olarak 0.05 kullanılmış olup; $\mathrm{p}<0.05$ olması durumunda anlamlı bir farklılığın olduğu, p>0.05 olması durumunda ise anlamı bir farklılığın olmadığı belirtildi.

\section{BULGULAR}

\section{Nabız değerlerinin karşılaştırılması}

'Anlat-göster-uygula' yönteminin uygulandığı 1. grupta, tüm zamanlarda ölçülen nabız değerleri arasında istatistiksel olarak anlamlı farklılık bulundu $(p<0.05)$. Bu grupta lokal anestezi öncesi ve sonrasında ölçülen nabız değerlerinin, çekimden sonra elde edilen nabız değerlerine göre anlamlı derecede düşük olduğu gözlendi.

$3 D$ video gözlük uygulanan 2. grupta tüm zaman dilimlerinde ölçülen nabız değerleri arasında da istatistiksel olarak anlamlı farklılık bulundu $(p<0.05)$. 3D video gözlük grubunda; çekim öncesi ölçülen nabız değerlerinin çekimden sonra ölçülen nabız değerlerine göre anlamlı derecede düşük olduğu saptandı (Tablo 1). 
Tablo 2. Gruplar arasında saturasyon değerlerinin karşılaştırılması

\begin{tabular}{lllllllllll}
\hline & & $\mathbf{n}$ & Ort. & Ortanca & Min & Maks & SS & Sira ort. & z & p \\
\hline İşlemden önce & 3D video gözlük & 30 & 97.03 & 97 & 95 & 99 & 1.25 & 25.5 & -2.271 & 0.023 \\
saturasyon & Anlat-göster-uygula & 30 & 99.47 & 98 & 95 & 150 & 9.64 & 35.5 & & \\
& Toplam & 60 & 98.25 & 97.5 & 95 & 150 & 6.92 & & & \\
Lokal anestezi & 3D video gözlük & 30 & 96.67 & 97 & 89 & 100 & 2.17 & 23.95 & -2.984 & 0.003 \\
sırasında saturasyon & Anlat-göster-uygula & 30 & 98.03 & 98 & 95 & 99 & 1.19 & 37.05 & & \\
& Toplam & 60 & 97.35 & 98 & 89 & 100 & 1.87 & & & \\
Lokal anestezi & 3D video gözlük & 30 & 96.27 & 96 & 93 & 98 & 1.34 & 21.35 & -4.145 & 0.001 \\
sonrası saturasyon & Anlat-göster-uygula & 30 & 98.77 & 98 & 95 & 128 & 5.63 & 39.65 & & \\
& Toplam & 60 & 97.52 & 97 & 93 & 128 & 4.25 & & & \\
Çekimden sonra & 3D video gözlük & 30 & 97.33 & 97 & 96 & 99 & 1.09 & 24.7 & -2.665 & 0.008 \\
saturasyon & Anlat-göster-uygula & 30 & 98.03 & 98 & 94 & 99 & 1.13 & 36.3 & & \\
& Toplam & 60 & 97.68 & 98 & 94 & 99 & 1.16 & & & \\
\hline
\end{tabular}

n: denek sayISI, Ort: ortalama, Min: minimum, Maks: maksimum, SS: standart sapma, SIra ort.: sıra ortalamasI ( $p<0.05$ istatistiksel olarak anlamli; Mann-Whitney U testi)

İki grup karşılaştıııldı̆ında nabız değerleri bakımından aralarında anlamlı farklılık bulunmadı ( $p>0.05)$. Ancak 'Anlat-göster-uygula' grubundaki nabız ölçüm değerleri arasındaki farkın, '3D video gözlük' grubuna göre daha fazla olduğu göze çarptı.

\section{Saturasyon değerlerinin karşılaştırılması}

Saturasyon değerlerine bakıldığında; 'Anlat-göster-uygula' grubunda, zamanlar arasında istatistiksel olarak anlamlı bir farklılık bulunmadı ( $p>0.05)$. 3D video gözlük grubunda ise farklı zamanlarda ölçülen saturasyon değerleri arasında istatistiksel olarak anlamlı farklılık bulundu $(p<0.05)$. Bu grupta, lokal anestezi sonrası saturasyon değerinin diş çekiminden sonra ölçülen saturasyon değerine göre anlamlı derecede düşük olduğu gözlendi (Tablo 1).

İşlemler öncesinde, lokal anestezi sırasında, lokal anestezi sonrasında ve diş çekiminden sonra ' $3 \mathrm{D}$ video gözlük' grubunun saturasyon değerleri, 'Anlat-gösteruygula' grubuna göre anlamlı derecede daha düşük bulundu $(\mathrm{p}<0.05)$ (Tablo 2).

\section{MCDAS değerlerinin karşılaştırılması}

MCDAS skala değerlerine bakıldığında hem 'Anlat-göster-uygula' grubunda hem de '3D video gözlük' grubunda kaydedilen ölçümler arasında grup içerisinde istatistiksel olarak anlamlı bir farklııı bulunmadı ( $p>0.05)$ (Tablo 3). İki grup arasındaki MCDAS skala değerleri karşılaşıııılığında istatistiksel olarak anlamlı bir farklılık gözlenmedi ( $p>0.05)$.

\section{Wong-Baker skala değerlerinin karşılaştırılması}

Lokal anestezi ve diş çekimi sonrası elde edilen W-B değerleri 'Anlat-göster-uygula' grubunda istatistiksel olarak anlamlı bir farklılık göstermedi ( $p>0.05)$. '3D video gözlük grubunda' ise W-B değerleri ölçülen zamanlar arasında istatistiksel olarak anlamlı bir farklılık gösterdi $(p<0.05)$. '3D video gözlük grubunda' diş çekiminden sonra ölçülen W-B değerinin lokal anestezi sonrası ölçülen W-B değerine göre anlamlı derecede düştüğü gözlendi. 'Anlat-göster-uygula' ve '3D video gözlük' grupları karşılaştırıldığında, diş çekiminden sonra ölçülen W-B değerleri arasında istatistiksel olarak anlamlı bir farklılık bulundu $(p<0.05)$. '3D video gözlük grubunda' diş çekimden sonra kaydedilen W-B değerlerinin 'Anlat-göster-uygula' grubuna göre anlamlı derecede düşük olduğu tespit edildi (Tablo 4).

\section{TARTIŞMA}

Anksiyete, insanlarda bilinmeyen bir duruma karşı oluşan tepki olarak tanımlanır ve preoperatif anksiyete ile artmış postoperatif ağrı gibi çok geniş kapsamlı etkiler yaratır. Pek çok diş hekimi diş tedavisine bağı olarak duyulan korku ve kuruntular nedeniyle gelişen dental anksiyete ile başa çıkmak durumunda kalmaktadır. Son

Tablo 3. Lokal anestezi öncesi ve sonrasında elde edilen MCDAS değerleri

\begin{tabular}{lllllllllll}
\hline & & $\mathbf{n}$ & Ort. & Ortanca & Min & Maks & SS & Sıra ort. & z & P \\
\hline 3D video gözlük & $\begin{array}{l}\text { MCDAS Skalası } \\
\text { (Anestezi Öncesi) }\end{array}$ & 30 & 13.7 & 13 & 6 & 21 & 3.83 & 12.62 & -0.403 & 0.687 \\
& $\begin{array}{l}\text { MCDAS Toplam } \\
\text { (Anestezi Sonrası) }\end{array}$ & 30 & 13.5 & 13 & 8 & 21 & 3.59 & 12.36 & \\
\hline Anlat-göster-uygula & $\begin{array}{l}\text { MCDAS Skalası } \\
\text { (Anestezi Öncesi) } \\
\text { MCDAS Toplam }\end{array}$ & 30 & 14.53 & 14 & 9 & 26 & 4.3 & 14.88 & -1.696 & 0.09 \\
& 30 & 13.5 & 12 & 6 & 27 & 4.91 & 8.25 & \\
\hline
\end{tabular}

n: denek sayısı, Ort: ortalama, Min: minimum, Max: maksimum, SS: standart sapma, Sıra ort.: sıra ortalaması ( $p<0.05$ istatistiksel olarak anlamlı, Wilcoxon testi) 
Tablo 4. Gruplar arasında Wong-Baker değerlerinin karşılaştırılması

\begin{tabular}{lllllllllll}
\hline & & $\mathbf{n}$ & Ort. & Ortanca & Min & Maks & SS & Sıra ort. & z & P \\
\hline Lokal anestezi & 3D video gözlük & 30 & 3.33 & 2 & 0 & 10 & 3.28 & 29.1 & -0.638 & 0.523 \\
sonrası & Anlat-göster-uygula & 30 & 3.73 & 2 & 0 & 10 & 3.05 & 31.9 & & \\
& Toplam & 60 & 3.53 & 2 & 0 & 10 & 3.15 & & & \\
Diş çekimden & 3D video gözlük & 30 & 1.87 & 0 & 0 & 10 & 2.87 & 25.87 & -2.156 & 0.031 \\
sonra & Anlat-göster-uygula & 30 & 3.53 & 2 & 0 & 10 & 3.35 & 35.13 & & \\
& Toplam & 60 & 2.7 & 2 & 0 & 10 & 3.21 & & \\
\hline
\end{tabular}

n: denek sayısı, Ort: ortalama, Min: minimum, Maks: maksimum, SS: standart sapma ( $p<0.05$ istatistiksel olarak anlamlı, Mann-Whitney U testi)

dönemlerde sanal gerçeklik ve 3D video gözlüklerin kullanımı ile anksiyete ve ağrının azaltıması gündeme gelmiştir. 3D video gözlüklerin travmatik yaralanmalar, yanık tedavisi, kemoterapi, enjeksiyon, fizyoterapi gibi medikal alanlarda ağrı ve anksiyete üzerinde olumlu etkilerini gösteren çalışmalar olduğu bildirilmiştir. ${ }^{13,14} \mathrm{Bu}$ gözlükler, kişiyi yapılan işlemden uzaklaştırarak dikkati başka yöne çevirmektedir. Dikkatin yeniden yönlendirilmesi ile gelen ağıı sinyallerinin yorumlama şeklini değiştirdiği ve böylece ağrılı beyin aktivitesi miktarını azalttı̆ı̆ belirtilmektedir. ${ }^{14}$

Diş hekimine ilk ziyareti olan çocuk hastalar, bilinmeyen diş hekimliği malzemeleri ve deneyimle karşılaştıkları için çoğunlukla endişelidir. 3D video gözlüklerin yüzü küçük olan hastalarda ve 7 yaş altı hastalarda kullanımının kısıtlı olması; baş ağrısı, kusma yapabilir olması, çocukla olan iletişimi engelleme, gözlük camının, kulaklığın sterilizasyonu ve pahalı olması gibi dezavantajları belirtilse ${ }^{6}$ de dental tedaviler sırasında çocukların dikkatini dağıtmak ve algıladıkları ağrı miktarını azaltmak için başarıı bir şekilde kullanılabileceğini gösteren çalışmalar bulunmaktadır. 2,10,15

Sunulan çalışmada, 6-10 yaş arası çocukların lokal anestezi ve diş çekimi sırasında 3D video gözlük kullanımının ağıı algısı ve anksiyete üzerindeki etkileri araştırılmıştır. Bilindiği gibi, diş çekimi hem erişkin hastalar hem de çocuk hastalar için anksiyete yaratan bir işlemdir. Cademartori ve ark. ${ }^{16}$ tarafından 6-13 yaş arası çocuklarla yapılan çalışma sonuçlarına göre flor uygulaması, dental profilaksi, rubber-dam uygulaması ve lokal anestezisiz dental restorasyon uygulamasıyla karşılaştırıldığında diş çekiminin daha fazla kooperasyon bozukluğu yaptığını belirtmişlerdir. Aynı zamanda endişe seviyesi yüksek olan çocukların dental tedavi sırasında ağıı ve anksiyeteyi yüksek düzeyde algıladığı; dikkat dağıtma tekniklerine cevap vermediği belirtilmiştir. ${ }^{14,17}$ Çalışmamızda, Frankl davranış skalasına göre 3 (pozitif) veya 4 (kesinlikle pozitif) olarak belirlenen çocuklar seçilerek uyum gösterme kabiliyetlerinin yüksek olması tercih edilmiştir.

Bu çalışmada, çocuklarda görsel-işitsel yöntemlerin değerlendirildiği çalışmalara benzer şekilde yapılan nabız ve oksijen saturasyon ölçümleri, stres ve anksiyetenin güvenilir bir göstergesi olarak kullanılmıştır. ${ }^{6,15}$ Yapılan değerlendirmede nabız değerleri açısından iki grup arasında anlamlı bir farklılık bulunmamakla birlikte, diş çekimi sonrasındaki nabız değeri, diş çekimi öncesindeki değere göre daha yüksek olarak kaydedilmiştir. Bu durum, diş çekimi işleminin lokal anestezi işleminden daha stresli bir prosedür olduğu şeklinde yorumlanabilir. 3D video gözlük uygulanan gruplarda Sullivan ve ark. ${ }^{9}$ lokal anestezi uygulaması sırasında ölçülen nabız değerinin uygulama öncesinde ölçülen değere göre düştüğünü belirtse de, bizim çalışmamızda olduğu gibi lokal anestezi uygulaması sırasında ölçülen nabız değerinin yüksek bulunduğu çalışmalar da mevcuttur. ${ }^{6,18}$ Chaturvedi ve ark. ${ }^{19}$ dental restorasyon sırasında uygulanan 3D gözlük ve kontrol grubunun nabız değerleri arasında anlamlı farklılık gözlemlerken; pulpa tedavisi ve dental profilaksi uygulamalarında bu çalışma sonuçlarına benzer biçimde farklılık kaydetmemişlerdir. Nuvvula ve ark. ${ }^{6}$ dikkat dağıtma yöntemlerinin kullanıldığı gruplarda gözlenen nabız artışının önemsiz olduğunu vurgulamıştır. Çalışmamızın sonuçları da bu bulguyu destekler niteliktedir. Ancak lokal anestezi öncesi ve sırasındaki ölçümlerinde sunulan çalışmanın sonuçlarının aksine MCDAS değerlerinde iki grup arasında anlamlı farklılık gözlemlemişlerdir.

Çalışmamızda iki grubun nabız değerlerinde farklılık görünmemesine karşın, '3D video gözlük' grubunda ölçülen saturasyon değerleri, 'Anlat-göster-uygula' grubuna göre anlamlı derecede daha düşük bulunmuştur. Ancak nabız değerlerine benzer şekilde '3D video gözlük' grubunda ölçülen saturasyon değerleri diş çekiminden sonra anlamlı derecede artmıştır. Bu durum, diş çekiminin diğer işlemlerden daha stresli bir prosedür olduğu şeklindeki yorumumuzu desteklemektedir.

MCDAS, dental işlemler sırasında çocuklarda geniş yaş aralığında kaygıyı değerlendirmek için kullanılan geçerli ve güvenilir bir skaladır. ${ }^{6}$ Her soru için 5 resimli cevap içeren 5 sorudan oluşmaktadır. MCDAS ölçeğindeki puanlar, 5 'ten 25 'e kadar değişebilir. ${ }^{20}$ Çaışmamızda MCDAS nabız ve saturasyon ölçümüne ek olarak, çocukların işleme başlamadan önceki ve lokal anestezi yapıldıktan sonraki endişelerini kaydetmek için kullanılmıştır.

$3 \mathrm{D}$ video gözlüklerinin kullanımı, genellikle hasta ile hekim arasındaki güven oluşturulduktan sonra önerilmektedir. ${ }^{10}$ Bu çalışmada hem her iki grup içindeki tedavi aşamaları karşılaşıııılığında; hem de iki grup birbiriyle karşılaştıııldığında, MCDAS değerlerinin anlamlı farklılık göstermemesi bu durum ile ilişkili olabilir. Daha önce hasta ile hekim arasında güven ilişkisini sağlayan bir randevu oluşturulmasının ardından gelen randevu- 
da, 3D video gözlük kullanımının endişe değerlerini düşüreceği düşünülmektedir. Çocuğun diş tedavileri sürecinde, bu görsel-işitsel davranış yönlendirme tekniklerinin uygulanması olumlu deneyimler elde etmesine ve dolayısıyla endişenin azaltılarak daha az ağıı algısı oluşmasına yardımcı olur.

W-B ağrı skalası dental işlemler sırasında algılanan ağrıyı değerlendirmek için kullanılır ve mutlu yüzden ağlayan yüze uzanan bir dizi fotoğraftan oluşur. Lokal anestezi uygulandıktan sonra ve diş çekiminden sonra çocuklardan, bu fotoğraflardan hangisinin kendisine daha yakın geldiğini göstermeleri istenir. ${ }^{21}$ Çalışmamızda, '3D video gözlük' grubunda, 'Anlat-göster-uygula' grubuna göre diş çekimi sonrası W-B ağrı skala değerleri daha düşük kaydedilmiştir. Bu sonuçlar, sırasıyla 6-8 ve 4-8 yaş arası çocukların süt molar dişlerine yapılan pulpa tedavileri sırasında 3D video gözlük kullanılmasının algılanan ağrıyı azalttığını gösteren çaIışmalarla uyumludur. ${ }^{14,22}$ El-Sharkawi ve ark. ${ }^{23}$ yaptığ çalışmada 3D video gözlük kullanımının lokal anestezi sırasında ve sonrasında yapılan ağrı değerlendirmelerinde kontrol grubuna göre anlamlı derecede düşük bulunmuştur. Bu çalışmada, ağrı değerlendirmesi lokal anestezi uygulaması sonrasında yapılmış olup; diş çekiminden sonra kaydedilen skorlar, lokal anesteziden hemen sonraki değerlere göre daha düşük bulunmuştur. Bu durumda, video gözlüklerin diş çekimi esnasındaki dikkat dağıtma etkisinin lokal anestezi uygulama sırasındaki etkisinden daha fazla olduğu söylenebilir.

Attar \& Baghdadi $^{8}$ tarafından yapılan bir çalışmada iPad ve video gözlük ağrı ve davranış skorları açısından karşılaştırılmış ve iPad'in daha başarılı olduğu sonucuna varılmıştır. Anksiyete değerlendirmelerini MCDAS skalasıyla ölçüp farklı sonuçlar almadıklarını, ancak ağrı ve davranış skorlarının, iPad kullanımında video gözlükten daha etkili olduğu sonucuna varmışlardır. iPad kullanımının daha etkin olması dikkat dağıtmada motor fonksiyonlarının da eklenmesinden kaynaklandığı düşünülmektedir. Ancak video gözlüklerin, görüntüleri kullanıcının gözünün önüne yansıtan ve dış dünyanın görsel ve işitsel uyaranlarını engellemesi nedeniyle ekrandan izlenen videolardan daha etkin olduğu da belirtilmektedir.²

Shah \& Bhatia'nın²4 '3D video gözlük' ve 'Anlat-oyna-uygula' tekniğini anksiyete açısından karşılaştırıldığı bir randomize kontrollü çalışmada, 'Anlat-oyna-uygula' tekniğinin '3D video gözlük' kadar etkin olduğu sonucuna varmıştır. Anksiyete azaltma yöntemi olarak 'Anlatoyna-uygula' yönteminin de '3D video gözlüğe' alternatif olarak kullanılabileceğini rapor etmişlerdir.

Bu çalışmanın limitasyonlarından biri, kullanılan lokal anestezi ve diş çekimi sürelerinin dental restorasyon sürelerine göre az olması ve 3D video gözlük kullanımı süresinin kısıtlı olmasıdır. Ayrıca 3D video gözlük, aynı hastada birden fazla randevuda kullanılarak, çeşitli dental tedavilerde çocuklardaki ağrı ve anksiyete üzerine olan etkisi daha fazla çalışma yapılarak değerlendirilebilir.

\section{SonUÇ}

Sonuç olarak, çocuklarda diş çekimi sırasında 3D video gözlük kullanımının anksiyete değerlerinde beklenen azalmayı sağlayamadığı; ancak ağrı algısını başarılı bir biçimde azalttığı görülmüştür. Genel olarak, 3D video gözlüklerin kullanımı, hasta ve diş hekimi arasında daha iyi bir ilişki kurulmasına ve sonraki randevularda hasta kooperasyonunun artmasına yardımcı olacaktır.

\section{KAYNAKLAR}

1. Simon DM, Corbett BA. Examining associations between anxiety and cortisol in high functioning male children with autism. J Neurodev Disord 2013;5:32.

2. Fakhruddin KS, Hisham EB, Gorduysus MO. Effectiveness of audiovisual distraction eyewear and computerized delivery of anesthesia during pulp therapy of primary molars in phobic child patients. Eur $\mathrm{J}$ Dent 2015;9:470-5.

3. Bentsen B, Wenzela A, Svensson P. Comparison of the effect of video glasses and nitrous oxide analgesia on the perceived intensity of pain and unpleasantness evoked by dental scaling. Eur J Pain 2003;7:49-53

4. Mahesh R, Prasad V, Menon PA. A case of accidental aspiration of an endodontic instrument by a child treated under conscious sedation. Eur J Dent 2013;7:225-8.

5. Buchanan H, Niven N. Self-report treatment techniques used by dentists to treat dentally anxious children: a preliminary investigation. Int J Paediatr Dent 2003;13:9-12.

6. Nuvvula S, Alahari S, Kamatham R, Challa RR. Effect of audiovisual distraction with $3 \mathrm{D}$ video glasses on dental anxiety of children experiencing administration of local analgesia: a randomised clinical trial. Eur Arch Paediatr Dent 2015;16:43-50

7. Bentsen B, Svensson P, Wenzel A. The Effect of a New Type of Video Glasses on the Perceived Intensity of Pain and Unpleasantness Evoked by a Cold Pressor Test. Anesth Prog 1999;46:113-7.

8. Attar RH, Baghdadi ZD. Comparative efficacy of active and passive distraction during restorative treatment in children using an iPad versus audiovisual eyeglasses: a randomised controlled trial. Eur Arch Paediatr Dent 2015;16:1-8.

9. Sullivan C, Schneider PE, Musselman RJ, Dummett CJ, Gardiner D. The effect of virtual reality during dental treatment on child anxiety and behavior. ASDC J Dent Child 2000;67:193-6.

10. Ram D, Shapira J, Holan G, Magora F, Cohen S, Davidovich E. Audiovisual video eyeglass distraction during dental treatment in children. Quintessence Int 2010;4:673-9.

11. Mathur J, Diwanji A, Sarvaiya B, Sharma D. Identifying Dental Anxiety in Children's Drawings and correlating It with Frankl's Behavior Rating Scale. Int J Clin Pediatr Dent 2017;10:24-8.

12. Howard KE, Freeman R. Reliability and validity of a faces version of the Modified Child Dental Anxiety Scale. Int J Paediatr Dent 2007;17:281-8.

13. Aminabadi NA, Erfanparast L, Sohrabi A, Oskouei SG, Naghili A. The impact of virtual reality on pain and anxiety during dental treatment in 4-6 year-old children: a randomized controlled clinical trial. J Dent Res Clin Dent Prospect 2012;6:117-24.

14. Panda A. Effect of virtual reality distraction on pain perception during dental treatment in children. Int J Oral Care Res 2017;5:1-4.

15. Kaur R, Jindal R, Dua R, Mahajan S, Sethi K, Garg S. Comparative evaluation of the effectiveness of audio and audiovisual distraction aids in the management of anxious pediatric dental patients. J Indian Soc Pedod Prev Dent 2015;33:192-203.

16. Cademartori MG, Martins $P$, Romano AR, Goettems ML. Behavioral changes during dental appointments in children having tooth extractions. J Indian Soc Pedod Prev Dent 2017;35:223-8. 
17. Aminabadi NA, Erfanparast L, Sohrabi A, Oskouei SG, Naghili A The impact of virtual reality distraction on pain and anxiety during dental treatment in 4-6 year-old children: a randomized controlled clinical trial. J Dent Res Dent Clin Dent Prospects 2012; 6:117-24.

18. Jimeno FG, Bellido MM, Fernández CC, Rodríguez AIL, Pérez JL, Quesada JRB. Effect of audiovisual. distraction on children's behaviour, anxiety and pain in the dental setting. Eur J Paediatr Dent 2014;15:297-302

19. Chaturvedi $S$, Walimbe $H$, Karekar $P$, Nalawade $H$, Nankar $M$, Nene K. Comparative evaluation of anxiety level during the conventional dental procedures with and without audiovisual distraction eyeglasses in pediatric dental patients. J Int Oral Health 2016;8:1016-22.

20. Facco E, Gumirato E, Humphris, Stellini E, Bacci C, Sivolella S, et al. Modified dental anxiety scale: validation of the Italian version Minerva Stomatol 2015;64:295-307.

21. Newman CJ, Loleka R, Limkittikul K, Chotpitayasunondh T, Chanthavanich P. A comparison of pain scales in Thai children. Arch Dis Child 2005;90:269-70

22. Niharika P, Reddy NV, Srujana P, Srikanth K, Daneswari V, Geetha KS. Effects of distraction using virtual reality technology on pain perception and anxiety levels in children during pulp therapy of primary molars. J Indian Soc Pedod Prev Dent 2018;36:364-9.

23. El-Sharkawi HFA, El-Housseiny AA, Aly AM. Effectiveness of New Distraction Technique on Pain Associated With Injection of Local Anesthesia for Children. Pediatr Dent 2012;34:142-5.

24. Shah U, Bhatia R. Effectiveness of Audiovisual Distraction Eyeglass Method Compared to Tell-Play-do Technique Among 4-7year-old Children: A Randomized Controlled Trial. Int J Oral Care Res 2018;6:1-7.

\section{The effect of 3D video glasses on pain and anxiety during primary molar teeth extraction in children}

\section{ABstract}

OвJective: Pediatric dentists have many methods to control anxiety and pain in children, and distracting the children appears to be the one of the most commonly used behavior management technique during dental procedures. The aim of this study was to evaluate the effectiveness of 3D video glasses that provide visual and auditory distraction during the extraction of molar teeth in children aged 6-10 years on anxiety and pain perception.

Materials AND Method: Sixty children between the ages of 6-10 years were randomly divided into two groups. Tooth extraction was performed by using tell-show-apply method to $\mathbf{3 0}$ patients in the first group. In the second group, 30 patients underwent tooth extraction while watching cartoons with 3D video glasses. Anxiety assessments of the children were performed with pulse and oxygen saturation measurements and MCDAS (Modified Child Dental Anxiety Scale) scores before the treatment, during local anesthesia and after local anesthesia. Pain perception was recorded with Wong-Baker (W-B) scale both after local anesthesia and after tooth extraction.

RESULTS: No significant difference was found in pulse and MCDAS scale values when tell show do and 3D video glasses groups were compared. All saturation measurements of the 3D video glasses group were found to be significantly lower than the tell show do group. In 3D video glasses group, after tooth extraction the recorded W-B values recorded significantly lower than the tell show do group.

ConcLusion: Although the use of 3D video glasses during tooth extraction in children did not provide the expected reduction in anxiety values, pain perception was found to decrease successfully.

KEYWORDS: Dental anxiety; pain perception; pediatric dentistry; virtual reality 